\title{
Applications of Third Order Models in Solvolytic Reaction of Aliphatic Substituted Acyl Derivatives in 2,2,2-Trifluoroethanol-Ethanol Systems
}

\author{
Zoon Ha Ryu, ${ }^{*}$ Gui Taek Lim, ${ }^{\dagger}$ and T. William Bentley ${ }^{\ddagger}$ \\ Department of Chemistry, Dong-Eui Chiversity, Busan 614-714. Korea \\ - Department of Chemistriv. Dong-A Universit, Busan 604-714, Korea \\ Eepartment of Chemistry, University of Hales, Swansea, Singleton Park. Swansea $\mathrm{S} 428 P P, U K$ \\ Received June 5, 2003
}

\begin{abstract}
Rate constants at various temperatures and activation parameters are reported for solvolyses of acyl chlorides (RCOCl). with $\mathrm{R}=\mathrm{Me}$, Et. $i$-Pr. $t-\mathrm{Bu}$, cyclopentylmethyl. benzyl. thiophenylmethyl, 2-phenylethyl, diphenylmethyl, and phenylthiomethyl in $100 \%$ ethanol. $100 \%$ 2.2,2-trifluoroethanol (TFE). $80 \%$ v/v ethanol/ water and $97 \% \mathrm{w} / \mathrm{w}$ TFE/water. Additional rate constants for solvolyses with $\mathrm{R}=\mathrm{Me}$. $t-\mathrm{Bu}$. and $\mathrm{PhCH}_{2}$ are reported for TFE/water and TFE/ethanol mixtures. and for solvolyses with $\mathrm{R}=t-\mathrm{Bu}$, and $\mathrm{PhCH}_{z}$ are reported for 1.1,1,3,3.3-hexafluoropropan-2-ol/water mistures, as well as selected kinetic solvent isotope effects (MeOH/MeOD and TFE). Taft plots show that electron withdrawing groups (EWG) decrease reactivity significantly in TFE, but increase reactivity slightly in ethanol. Correlation of solvent effects using the extended Grunwald-Winstein (GW) equation shows an increasing sensitivity to solvent nucleophilicity for EWG. The effect of solvent stoichiometry in assumed third order reactions is evaluated for TFE/ethanol nixtures, which do not fit well in $\mathrm{GW}$ plots for $\mathrm{R}=\mathrm{Me}$. and $t$ - $\mathrm{Bu}$, and it is proposed that one molecule of TFE may have a specific role as electrophile: in contrast. reactions of substrates containing an EWG can be explained by third order reactions in which one molecule of solvent (ethanol or TFE) acts as a nucleoplile. and a molecule of ethanol acts as a general base catalyst. Isokinetic relationships are also investigated.
\end{abstract}

Key Words : Solvolysis, Kinetics, Acyl chlorides, Solvent effects

\section{Introduction}

Studies of the stabilization of carbocation intermediates $\left(\mathrm{C}^{-}\right)$and transition states for solvolytic reactions in aqueous organic solvent systems have been performed as one of the important projects for a long time. The main factors related to the stabilization have been found to be the polar solvent effect (the ionizing power. $Y)^{l}$ and the resonance effect:recently Brönsted type solvation effect (tertiary alkyl cation) ${ }^{3}$ and more a hydrophilic substituent effect. ${ }^{4}$ have also been considered. Nucleophilic solvent participation on carbocations for solvolytic reactions has been interesting (so $\mathrm{far}^{5}{ }^{5}$ since an appreciation of the nucleophilic solvation of $\mathrm{C}^{+}$ in solvolyses of tert-butyl chloride $(t-\mathrm{BuCl})$, which brought about a more suitable new $\mathrm{S}_{\mathrm{N}} \mathrm{l}$ model compound. was reported by Kevill ${ }^{6}$ and the micleophilic and the electrophilic solvation effect for these reactions of benzy $\mathrm{r}^{7.8}$ and benzoyl systems ${ }^{9.10}$ (led by the introduction of $\dot{C}=0$ group into benzyl system) were also found out in fluorinated alcohol system faxoring carbocation [including 2.2.2-trifluoroethanol (TFE)-ethanol sy stem as medium].

Solvolyses of series of aliphatic acyl chlorides ${ }^{11}$ (parent compound: $\mathrm{CH}_{3} \mathrm{COCl}$ ), were reported by Kevill ${ }^{2.13}$ as $\mathrm{S}_{4} \mathrm{~N}$ mechanism in ethanolyses (highly nucleophilic media) and as (second) third order reactions by general base catalyzed (GBC) by a molecule of solvent in methanolyses, respectively. Whereas. in aqueous solvent systems, solvolytic reactions

\footnotetext{
Corresponding author. E-mail: Zhryulotdongeui.ac.kr
}

for $\mathrm{CH}_{3} \mathrm{COCl}$ and trimethyl acetyl chloride $\left[\left(\mathrm{CH}_{3}\right)_{3} \mathrm{COCl}\right]$ possessing a bulky alkyl group. were evaluated by Bentley $^{1+.15}$ as the bimolecular reaction (no GBC) and as the competing reaction channel. respectively according to the variation of the solvent composition. More recently. for solvolyses of substituted acetyl chlorides containing sulfur atoms in aqueous organic solvent șistems including TFEethanol solvent sy'stems, the same reactivity with relatively large nucleophilic solvation of the carbonyl group $(\mathrm{C}=\mathrm{O})$ relative to the electrophilic solvation were also investigated by Ryu. ${ }^{k i}$

Other investigations for carbonyl compounds include the effect of the groups adjacent to the reaction center $(C=O)$ in studies of kinetic and mechanism of aminolysis ${ }^{17-19}$ and py ridinoly sis ${ }^{2(121}$ of substituted acylate compounds: observed effects are small. with substrates undergoing the same stepwise mechanism.

Our research has been conducted to obtain further information on the possible effect of adjacent groups and a possible application of third order models to solvoly ses with nucleophilic participation in transition states (TS) with variable carbocation character. Aliphatic substituted acyl derivatives (Scheme) undergoing addition-elimination $\left(\mathrm{S}_{4} \mathrm{~N}\right)^{12.13}$ and /or $\mathrm{S}_{N} 2 / \mathrm{S}_{\mathrm{S}} \mathrm{1}^{16 \mathrm{i}}$ mechanism are chosen as the substrates for our work and the solvent systems chosen are as mentioned below:

TFE and ethanol are well known for contrasting ${ }^{22.23}$ nucleophilicity and polarity: 100\%TFE (solvent nucleophilicity. $\mathrm{N}_{\mathrm{T}^{24.25}}^{24.93}$ and solvent ionizing power. $\mathrm{Y}_{\mathrm{Cl}}{ }^{26 .}: 2.79$ ) 


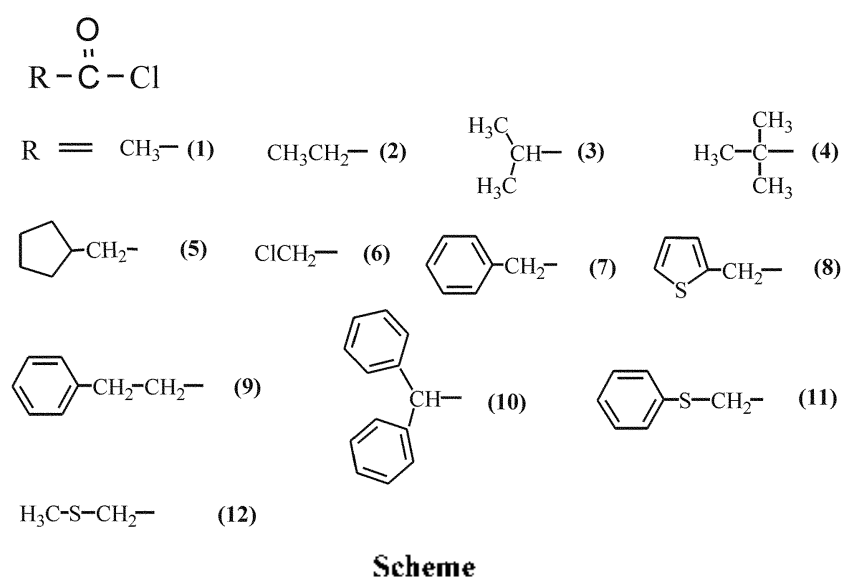

and $100 \%$ ethanol $\left(\mathrm{N}_{\mathrm{l}}-0.37\right.$ and $\left.\mathrm{Y}_{\mathrm{Cl}}--2.5\right)$. Kinetic studies of solvolyses in these alcohols probe for nucleophilic solvent assistance in solvolysis even though the two alcohols have dielectric constant which are closely similar $\left(\varepsilon_{1 / \mathrm{L}}-\right.$ 26.14 and $\varepsilon_{\text {elhanol }}-24.32$ at $25^{\circ} \mathrm{C}$ ). ${ }^{27}$ Also 97\% (w/w) 2,2,2trifluoroethanol-water $(97 \mathrm{~T})$ has a similar nucleophilic property to formic acid $\left(\mathrm{N}_{\mathrm{Bs}}{ }^{28}--2.59\right.$ for $97 \mathrm{~T}$ and -2.05 for $\left.\mathrm{HCO}_{2} \mathrm{H}\right)^{20}$ and $80 \%(\mathrm{v} / \mathrm{v})$ ethanol-water $(80 \mathrm{E})$ is the standard solvent for the solvent effects. As binary solvent mixtures for solvolyses, we studied TFE-ethanol solvent systems, which have a large negative gradient in the relationship ${ }^{22}$ of solvent nucleophilicity $(\mathrm{N})$ with solvent ionizing power ( $\mathrm{Y}$, based on 2-adamantyl tosylate) as their mixtures composition are varied, and TFE-water solvent systems with a drastic decrease in $\mathrm{N}^{22,2.3}$ with an increase in TFE content. Additional solvent systems were chosen to be 1,1,1,3,3,3-hexafluoro-2-propanol (HFIP)-water solvent systems (a relatively acidic solvent).

Solvolysis rates are analyzed by Taft's polar correlation., Grunwald-Winstein plots, ${ }^{26.31-33}$ third order reaction models, kinetic solvent isotopic effect (KSIE) and Leffler's isokinetic relationship ${ }^{34}$ for the substrates shown in the scheme.

\section{Results}

Rate constants for solvolyses of substituted acyl derivatives of $1-11$ in $100 \%$ ethanol, $80 \mathrm{E}, 100 \%$ TFE and $97 \mathrm{~T}$ solvent systems at various temperatures and the activation parameters are shown Table I and rate constants for substituted acyl derivatives of 1,4 and 7 substituents in fluorinated alcohol systems at $0^{\circ} \mathrm{C}$ are also shown in Table 2.

\section{Discussion}

Polar and steric relationships. This relationship was expressed as the two-term Taft eq. (1) ${ }^{30}$ considered the role of both polar and steric effects, and has been extensively used for kinetics of the formation and hydrolysis of carboxylic ester. ${ }^{\text {it }}$

$$
\log \left(k / k_{\circ}\right)=\rho^{*} \sigma^{*}+\delta \Gamma_{s}
$$

In eq. (1), $k$ is the solvolytic rate constant for reaction of $\mathrm{RCOCI}, k_{0}$ is the rate constant for the standard compound [R
Table 1. l"irst order rate constants ${ }^{a}$ for solvolyses of aliphatic substituted acyl derivatives in solvent systems chosen at various temperatures $(\mathrm{T})$ and the activation parameters

\begin{tabular}{|c|c|c|c|c|c|}
\hline $\mathrm{R}$ in $\mathrm{RCOCl}$ & solvent & I. ${ }^{\circ} \mathrm{C}$ & foots $\times 10^{3} \mathrm{~s}^{-1}$ & $\begin{array}{c}\Delta \mathrm{H}^{i b} . \\
\text { kcalimole }\end{array}$ & $\begin{array}{c}\Delta S^{i b} . \\
\text { 니 }\end{array}$ \\
\hline \multirow[t]{13}{*}{$M c(1)-$} & $100 \% \mathrm{EtOH}^{\prime}$ & -10.0 & $8.58+0.01$ & 12.9 & -18.9 \\
\hline & & -5.0 & $14.1+0.1$ & & \\
\hline & & 0.0 & $21.9+0.4$ & & \\
\hline & $100 \% \mathrm{TFE}^{2 /}$ & -10.0 & $11.8+0.1$ & 11.2 & -24.6 \\
\hline & & -5.0 & $17.4+0.5$ & & \\
\hline & & 0.0 & $26.8+0.2$ & & \\
\hline & $80 \%(v / v) \mathrm{EtOH}^{\mathrm{c}}$ & -10.0 & $112=1.0$ & 13.8 & -10.3 \\
\hline & & -5.0 & $118=1.0$ & & \\
\hline & & 0.0 & $305^{\prime}$ & & \\
\hline & $97 \%(w)$ TFE & -13.6 & 18.7 & 13.7 & -13.2 \\
\hline & & -5.0 & $47.7 \pm 1.0$ & & \\
\hline & & 0.0 & $57.3^{\prime}$ & & \\
\hline & & 5.0 & 119 & & \\
\hline \multirow[t]{16}{*}{$\operatorname{Et}(2)-$} & $100 \% \mathrm{EtOH}^{\circ}$ & -12.8 & $7.79 \pm 0.05$ & 14.2 & $-13,4$ \\
\hline & & -10.0 & $10.5 \pm 0.5$ & & \\
\hline & & -5.0 & $17.8 \pm 1.1$ & & \\
\hline & & 0.0 & $29.0 \pm 0.7$ & & \\
\hline & $100 \% \mathrm{TFE}^{t t}$ & -12.6 & $6.74 \pm 0.04$ & 14.80 & -11.5 \\
\hline & & -10.0 & $8.50 \pm 0.04$ & & \\
\hline & & -5.0 & $15.4 \pm 0.2$ & & \\
\hline & & 0.0 & $25.8 \pm 0.4$ & & \\
\hline & $80(\mathrm{v} / \mathrm{v}) \% \mathrm{EtOH}$ & -12.4 & $57.1 \pm 0.6$ & 15.32 & +5.14 \\
\hline & & -10.0 & $78.3 \pm 1.0$ & & \\
\hline & & -5.0 & $141=9.0$ & & \\
\hline & & 0.0 & $229=3.0$ & & \\
\hline & $97(\mathrm{w}+\mathrm{t}) \% \mathrm{TFE}^{\prime}$ & -12.4 & $16.7 \pm 0.2$ & 13.1 & -15.9 \\
\hline & & -10.0 & $21.2 \pm 0.7$ & & \\
\hline & & -5.0 & $36.5 \pm 0.1$ & & \\
\hline & & 0.0 & $55.5 \pm 2.1$ & & \\
\hline \multirow[t]{14}{*}{$i-\operatorname{Pr}(3)-$} & $100 \% \mathrm{EtOH}^{\circ}$ & -10.0 & $7.56 \pm 0.1$ & 10.6 & -27.6 \\
\hline & & 0.0 & $16.9 \pm 1.5$ & & \\
\hline & & 10.0 & $34.2^{11}$ & & \\
\hline & $100 \% \mathrm{TFE}^{t t}$ & -10.0 & $5.6 \pm 0.1$ & & \\
\hline & & 0.0 & $14.0 \pm 0.7$ & & \\
\hline & & 10.0 & $32.8^{14}$ & & \\
\hline & $80 \%(v / v) \mathrm{EtOH}^{c}$ & -13.4 & $23.4 \pm 0.6$ & 13.8 & -12.8 \\
\hline & & -10.0 & $31.9 \pm 0.3$ & & \\
\hline & & 0.0 & $81.8 \pm 0.1$ & & \\
\hline & & 10.0 & $233^{\prime \prime}$ & & \\
\hline & $97 \%(w / y)$ TFE $^{u}$ & -10.0 & $15.5 \pm 0.2$ & 12.1 & -20.7 \\
\hline & & -5.0 & $24.5 \pm 0.1$ & & \\
\hline & & 0.0 & $37.1 \pm 0.3$ & & \\
\hline & & 5.0 & $57.2 \perp 1.0$ & & \\
\hline \multirow[t]{9}{*}{$t-13 u(4)-$} & $100 \% \mathrm{H}: 1 \mathrm{OH} \mathrm{l}^{\circ}$ & -10.0 & $1.14 \perp 0.09$ & 12.9 & -22.7 \\
\hline & & -50 & $1.89 \pm 0.09$ & & \\
\hline & & 0.0 & $2.48-0.0 \mathrm{I}^{i}$ & & \\
\hline & & 10.0 & $7.05 \perp 0.27$ & & \\
\hline & $100 \% 1 \mathrm{l} 1 \%$ & -10.0 & $1.34 \pm 0.1$ & 14.3 & -17.2 \\
\hline & & 0.0 & $3.60+0.01$ & & \\
\hline & & 10.0 & $9.93+0.66$ & & \\
\hline & $80 \%(v / v) \mathrm{l}: 10 \mathrm{H}$ & -10.0 & $5.7 \pm 0.3$ & 13.1 & -18.8 \\
\hline & & 0.0 & $13,4^{\prime}$ & & \\
\hline
\end{tabular}


Table 1. Continued

\begin{tabular}{|c|c|c|c|c|c|}
\hline $\mathrm{R}$ in $\mathrm{RCOCl}$ & solvent & T. ${ }^{\circ} \mathrm{C}$ & $k_{\mathrm{obs}} \cdot 10^{\hat{3}} \mathrm{~s}^{-1}$ & $\begin{array}{c}\Delta \mathrm{H}^{-b} \\
\text { keal mole }\end{array}$ & $\begin{array}{c}\Delta \mathrm{S}^{=b} \\
\text { ell }\end{array}$ \\
\hline \multirow[t]{4}{*}{$t-\mathrm{Bu}(4)-$} & & 25.0 & $120 \pm 2.0^{\prime}$ & & \\
\hline & $97^{\circ}$ o(w w) TFE & -10.0 & $3.14=0.04$ & 13.4 & -18.7 \\
\hline & & 0.0 & $8.66=0.01$ & & \\
\hline & & 10.0 & $20.7 \pm 0.2$ & & \\
\hline \multirow[t]{16}{*}{$\mathrm{CPCH}_{2}(5)^{k}-$} & $100^{\circ}{ }_{0} \mathrm{EtOH}^{\circ}$ & -13.1 & $6.24=0.01$ & 14.6 & -12.3 \\
\hline & & -10.0 & $8.38=0.12$ & & \\
\hline & & -5.0 & $14.5 \pm 0.5$ & & \\
\hline & & 0.0 & $25.2 \pm 0.1$ & & \\
\hline & $100^{\circ} . \mathrm{TFE}^{d}$ & -130 & $22.6 \pm 0.3$ & 13.4 & -14.2 \\
\hline & & -10.0 & $31.3 \pm 1.6$ & & \\
\hline & & -50 & $51.1 \pm 1.0$ & & \\
\hline & & 0.0 & $82.7 \pm 0.5$ & & \\
\hline & $80(v \psi)^{0}{ }_{0} \mathrm{EtOH}$ & -13.1 & $43.4 \pm 0.6$ & & \\
\hline & & -10.0 & $63.2 \pm 0.4$ & 16.0 & -2.8 \\
\hline & & -50 & $118 \pm 2.0$ & & \\
\hline & & 0.0 & $200=9$ & & \\
\hline & $97(w w)^{0}{ }_{0} \mathrm{TFE}^{\mathrm{g}}$ & -13.6 & $40.4 \pm 0.3$ & 15.2 & -6.1 \\
\hline & & -10.0 & $63.1 \pm 0.2$ & & \\
\hline & & -5.0 & $106=5$ & & \\
\hline & & 0.0 & $187=8$ & & \\
\hline $\mathrm{ClCH}_{2}(6)^{I}$ & $100^{\circ} \cdot \mathrm{EtOH}^{c}$ & -10.0 & $101 \pm 22$ & & \\
\hline \multirow[t]{12}{*}{$\mathrm{PhCH}_{2}(7)$} & $100^{\circ}{ }_{0} \mathrm{EtOH}^{c}$ & 0.0 & $20.4 \pm 1.0$ & 8.46 & -35.2 \\
\hline & & 5.0 & $27.2 \pm 0.3$ & & \\
\hline & & 10.0 & $36.7 \pm 0.3$ & & \\
\hline & $100^{\circ} \cdot \mathrm{TFE}^{d t}$ & -10.0 & $0.47 \pm 0.005$ & 12.6 & -25.6 \\
\hline & & -5.0 & $0.77=0.04$ & & \\
\hline & & 0.0 & $1.18=0.03$ & & \\
\hline & $80^{\circ} \circ(\mathrm{v} v) \mathrm{EtOH}^{e}$ & -10.0 & $24.4=0.07$ & 11.2 & -23.2 \\
\hline & & 0.0 & $54.7 \pm 2.0$ & & \\
\hline & & 10.0 & $119 \pm 2.0$ & & \\
\hline & $97^{\circ}$ o(w w) TFE & 0.0 & $3.04=0.01$ & 15.2 & -14.2 \\
\hline & & 10.0 & $7.88=0.01$ & & \\
\hline & & 20.0 & $22.1=0.28$ & & \\
\hline \multirow[t]{13}{*}{$\mathrm{TP}-\mathrm{CH}_{2}(\boldsymbol{8})^{m}-$} & $100^{\circ}{ }_{0} \mathrm{EtOH}^{c}$ & -10.0 & $13.4=0.07$ & 9.90 & -29.2 \\
\hline & & 0.0 & $29.3 \pm 0.6$ & & \\
\hline & & 10.0 & $54.8^{\prime \prime}$ & & \\
\hline & $100^{\circ}: \mathrm{TFE}^{d}$ & 0.0 & $0.193 \pm 0.01$ & 13.9 & -24.6 \\
\hline & & 10.0 & $0.423^{\prime \prime}$ & & \\
\hline & & 20.0 & $1.19=0.05$ & & \\
\hline & $80^{\circ}$ o(v) (v) $\mathrm{EtOH}^{e}$ & -10.0 & $36.8 \pm 0.9$ & 9.96 & -28.6 \\
\hline & & 0.0 & 75.0 & & \\
\hline & & 10.0 & $144^{\prime \prime}$ & & \\
\hline & $97^{\circ} \cdot(\mathrm{w} / \mathrm{w}) \mathrm{TFE}$ & 0.0 & $0.59 \pm 0.014$ & 14.4 & -20.5 \\
\hline & & 10.0 & $1.30^{\prime \prime}$ & & \\
\hline & & 20.0 & $3.75=0.03$ & & \\
\hline & & 30.0 & $8.69=0.19$ & & \\
\hline \multirow{7}{*}{$\begin{array}{l}\mathrm{PhCH}_{2} \mathrm{CH}_{2} \\
\text { (9)- }\end{array}$} & $100^{\circ} \cdot \mathrm{EtOH}^{\mathrm{c}}$ & -10.0 & $8.0 \pm 0.006$ & 13.0 & -18.4 \\
\hline & & 0.0 & $22.0 \pm 0.8$ & & \\
\hline & & 10.0 & $49.9 \pm 0.1$ & & \\
\hline & $100^{\circ} \cdot \mathrm{TFE}^{d}$ & -10.0 & $2.29=0.06$ & 14.9 & $-13,9$ \\
\hline & & 0.0 & $6.89=0.08$ & & \\
\hline & & 10.0 & $18.3 \pm 0.6$ & & \\
\hline & $80^{\circ}$ o(v) $(\mathrm{v}) \mathrm{EtOH}^{e}$ & -10.0 & $34.2 \pm 0.7$ & 13.1 & -15.1 \\
\hline
\end{tabular}

Table 1. Continued

\begin{tabular}{|c|c|c|c|c|c|}
\hline $\mathrm{R}$ in $\mathrm{RCOCl}$ & solvent & T. ${ }^{\circ} \mathrm{C}$ & $k_{\text {ubo: }} \cdot 10^{3}: \mathrm{s}^{-1}$ & $\begin{array}{c}\Delta \mathrm{H}^{\ddagger b} . \\
\text { kcal mole }\end{array}$ & $\begin{array}{c}\Delta \mathrm{S}^{-b} \\
\text { eul }\end{array}$ \\
\hline \multirow{5}{*}{$\begin{array}{l}\mathrm{PhCH}_{2} \mathrm{CH}_{2} \\
\text { (9)- }\end{array}$} & & 0.0 & $89.2=2.9$ & & \\
\hline & & 10.0 & $217 \pm 20$ & & \\
\hline & $97^{\circ} \cdot w(\mathrm{w}: \mathrm{w}) \mathrm{TFE}^{\mathrm{g}}$ & -10.0 & $5.82 \pm 0.05$ & 14.1 & -14.9 \\
\hline & & 0.0 & $15.9=0.2$ & & \\
\hline & & 10.0 & $42.2=0.4$ & & \\
\hline \multirow{14}{*}{$\begin{array}{l}(\mathrm{Ph})_{2} \mathrm{CH} \\
(\mathbf{1 0})_{-}\end{array}$} & $100^{\circ}{ }_{0}^{\circ} \mathrm{EtOH}^{c}$ & 0.0 & $9.01 \pm 0.12$ & 9.99 & -31.2 \\
\hline & & 10.0 & $15.7^{h}$ & & \\
\hline & & 20.0 & $37.8 \pm 0.02$ & & \\
\hline & & 30.0 & $57.0 \pm 0.01$ & & \\
\hline & $100^{\circ} \mathrm{TFE}^{d}$ & 0.0 & $0.163=0.06$ & 15.6 & -18.9 \\
\hline & & 10.0 & $0.370^{h}$ & & \\
\hline & & 20.0 & $1.03 \pm 0.04$ & & \\
\hline & & 30.0 & $3.02 \pm 0.22$ & & \\
\hline & $80\left(^{\circ} \mathrm{ov} v\right) \mathrm{EtOH}$ & 0.0 & $22.6=0.4$ & 11.0 & -25.6 \\
\hline & & 10.0 & $41.9^{h}$ & & \\
\hline & & 20.0 & $97.2=2.0$ & & \\
\hline & $97^{0} \cdot w(\mathrm{w} w) \mathrm{TFE}^{\underline{z}}$ & 0.0 & $0.35 \pm 0.01$ & 14.7 & -20.1 \\
\hline & & 10.0 & $0.94^{h}$ & & \\
\hline & & 20.0 & $2.4 \pm 0.1$ & & \\
\hline \multirow[t]{13}{*}{$\mathrm{PhSCH}_{2}(11)-$} & $100{ }^{\circ}{ }_{0} \mathrm{EtOH}^{c}$ & -10.0 & $12.6=0.3$ & 9.92 & -29.3 \\
\hline & & 0.0 & $27.5=0.1$ & & \\
\hline & & 10.0 & $51.7^{\prime \prime}$ & & \\
\hline & $100^{\circ}$.TFE & 0.0 & $0.143=0.01$ & 15.6 & -19.1 \\
\hline & & 10.0 & $0.33^{\prime 3}$ & & \\
\hline & & 20.0 & $1.09 \pm 0.04$ & & \\
\hline & $80^{\circ} .0(\mathrm{v} / \mathrm{v}) \mathrm{EtOH}$ & -10.0 & $30.5=1.0$ & 10.3 & -26.0 \\
\hline & & 0.0 & $68.0=0.4$ & & \\
\hline & & 10.0 & $132^{\prime \prime}$ & & \\
\hline & $\left.97^{\circ} \cdot(\mathrm{W}) \mathrm{W}\right) \mathrm{TFE}^{\mathrm{g}}$ & 0.0 & $0.485 \pm 0.008$ & 14.4 & -209 \\
\hline & & 10.0 & $1.11^{18}$ & & \\
\hline & & 20.0 & $3.04 \pm 0.01$ & & \\
\hline & & 30.0 & $7.26 \pm 0.29$ & & \\
\hline
\end{tabular}

Detenmined conductimetically at least in quadruplicate: trpically injected $4 \mu \mathrm{L}$ of $l^{\circ} \mathrm{o}(\mathrm{w}$ (w) substrate in dry acetonitrile into the kinetic apparatus with a turbo-stirrer containing $2 \mathrm{~mL}$ of eacl solvent systems: errors showin are the standard deviations. ${ }^{b} \mathrm{Calculated}$ from Evring plots. "Pure ethanol solvent. "Pure 2,2,2-trifluorothanol solvent. "80. o(v) ethanol-water solvent sustem. Data from ref. 14 . ${ }^{2} 97^{0} \cdot \mathrm{o}(\mathrm{w} / \mathrm{w})$ trifluoroethanol-water solvent system measured exactly as $96.87^{\circ} .0$ (witw) by using a Karl Fisher Titrator. "Data from ref. $35 .{ }^{j}$ Reported as $k=2.49 \times$ $10^{-3} \mathrm{~s}^{-1}$ in ref. 15 . Data from ref. 15 . ${ }^{k}$ Presented as crclophentyl acetyl chloride. 'Solvolysis rate in $100^{\circ}{ }_{0}$ TFE solvent was too slow to measure under our experimental condition. " $P$ resented as thiophenyl-2-acetyl chloride. "Data from ref. 16 [electronic supplementary information (ESI) available: TableSI-S3, see hittp: wiw wsc. ong suppdata p2:b2:b2026641" ].

$=\mathrm{Me}-(\mathbf{1})] \cdot \sigma^{*}$ is a polar substituent parameter for R- $\mathrm{E}_{\mathrm{s}}$ is a steric parameter for R- and $\rho^{*}$ and $\delta$ are susceptibilities for each substituent parameter, respectively:

Our work recognizes the formal similarity of solvolyses of acid chlorides and carboxylic esters. analyzed in terms of the eqn. (1). The results of correlation analysis inrolving multiple regression on $\rho^{*}$ and $\delta$ are tabulated in Table 3 .

Higher contributions of a polar effects $\left(0.65<\rho^{*}\right)$ relative to a steric effects (rather small: $0.18<\delta<0.50$ ) were obtained for solvolyses in pure ethanol and $80 \mathrm{E}$ (relatively 
Table 2. liirst order rate constants $\left(k \times 10 / \mathrm{s}^{-1}\right)$ tor solvolyses of various substituted acyl chloride in aqueous lluorinated alcohol and trifluorocthanol (T)-ethanol (E) solvent mixtures at 0 " $\mathrm{C}^{\mathrm{ct}}$

\begin{tabular}{cccc}
\hline Solvenl & $\mathrm{I}$ & 4 & 7 \\
\hline $90 \% \mathrm{TFE}$ & $209 \pm 1.0$ & $22.3 \pm 0.1$ & $9.17 \pm 0.01$ \\
$80 \% \mathrm{TFE}$ & $775 \pm 2.0$ & $54.9 \pm 0.2$ & $2.21 \pm 0.09$ \\
$70 \% \mathrm{TFE}$ & $1440^{c}$ & $164 \pm 1.0$ & $5.64 \pm 0.1$ \\
$60 \% \mathrm{TFE}$ & - & $268 \pm 5.0$ & - \\
$50 \% \mathrm{TFE}$ & - & $336 \pm 3.0$ & $1.12 \pm 0.02$ \\
$80 \mathrm{~T}-20 \mathrm{~L}^{d c}$ & $36.3 \pm 0.2$ & $4.90 \pm 0.06$ & $4.86 \pm 0.00$ \\
$60 \mathrm{~T}-40 \mathrm{C}^{d c}$ & $33.7 \pm 0.1$ & $4.17 \pm 0.01$ & $7.64 \pm 0.04$ \\
$50 \mathrm{~T}-50 \mathrm{~L}^{d c}$ & $31.4 \pm 0.1$ & $3.86 \pm 0.03$ & $9.46 \pm 0.05$ \\
$40 \mathrm{~T}-60 \mathrm{~L}^{d c}$ & $29.5 \pm 0.2$ & $3.46 \pm 0.01$ & $11.7 \pm 0.02$ \\
$20 \mathrm{~T}-80 \mathrm{~L}^{d c}$ & $26.2 \pm 0.1$ & $3.06 \pm 0.01$ & $16.1 \pm 0.06$ \\
$97 \% \mathrm{HFIP}^{d s}$ & - & $51.4 \pm 0.1$ & $7.52 \pm 0.02$ \\
$90 \% \mathrm{HFIP}^{\prime}$ & - & $58.3 \pm 0.1$ & $14.6 \pm 0.1 \mathrm{I}$ \\
$50 \% \mathrm{HFIP}^{\prime}$ & - & $269 \pm 0.4$ & $106 \pm 2$ \\
\hline
\end{tabular}

"Performed under the same condition as footnote al of Table $I$. "Percentage of wolvent composition batsed on weight/weight. 'Datal from rel. 14. "Percentage of solvent conmposition based on volumeivolume. ' $\mathrm{T}$ - $\mathrm{T}$ : is 2.2.2-TFF-ethanol solvent ststems. HFIP is $1,1,1.3 .3 .3$ hexafluore-2-propenol-water solvent systems. "Measured exactly as $97.31 \%(w / w)$ by using a Karl Fisher.

Table 3. Comelation of $\log \left(k / k_{s}\right)$ and $\log \left(k / k_{\mathrm{se}-(1)}\right)$ for solvolyses ol series of aliphalic substituled acelyl chloride sludied in this work at $0^{~ ' C ~}$ with Taft's single (polar) and dual (polar-steric) parameters ${ }^{t \prime}$

\begin{tabular}{|c|c|c|c|c|c|c|}
\hline Solvent & paramelers & $n^{b}$ & $1^{*}$ & $\rho^{* d f}$ & $8^{\prime}$ & $\mathrm{c}^{\mathrm{i}}$ \\
\hline \multirow[t]{2}{*}{ cthanol } & $\sigma^{*}$ & $5^{\prime}$ & 0.964 & 0.50 & & -0.593 \\
\hline & $\sigma^{*} . \mathrm{E}_{s}$ & 7 & 0.955 & 0.70 & 0.49 & 0.12 \\
\hline \multirow[t]{2}{*}{ TFE } & $\sigma^{*}$ & 7 & 0.995 & -2.27 & & -1.18 \\
\hline & $\sigma^{*} . \mathrm{E}_{s}$ & 7 & 0.975 & -2.08 & 0.62 & -0.40 \\
\hline $\begin{array}{c}80 \%(v / v) \\
\text { ethanol-water }\end{array}$ & $\sigma^{*} . \mathrm{E}_{\mathrm{s}}$ & 7 & 0.924 & 0.66 & 0.19 & -0.21 \\
\hline $97 \%(w / w)$ & $\sigma^{*}$ & 7 & 0.974 & -2.26 & & -0.760 \\
\hline Tll:-water & $\sigma^{*} .1:$ & 7 & 0.981 & -2.07 & 0.77 & -0.29 \\
\hline
\end{tabular}

"Llsed by polar $\left(\sigma^{*}\right)$ and steric (Es) parameters quoted from ref. 38 for aliphatic system within the range of all those known and $\log (h / k$ xis: $)$ were used for single regression parameter $\left(\sigma^{*}\right)(k$ knt: rate constant in $80 \%(v / v)$ ethanolwater solvent system) and $\log \left(k / k \mathrm{k}_{1}\right.$ (1) was used for dual

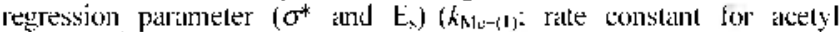
chleride). "Number of acyl derivatives used for cortelation. "Correlation coefficient. "Susceptibility to each parameter chosen. "Value of constant obtained from the correlation. 'Two poitts for $\mathbf{I}$ and $\mathbf{2}$ acyl derivatives were removed due to the deviation from correlation (as shown in rigure I)

nucleophilic solvents). Our results for ethanolyses are appreciably different from those reported previously ${ }^{12}$ (e.g. $\rho^{*}-0.547, \delta-0.527$ and $\mathrm{r}-0.933$ ). This is probably due to the different substituents analyzed $(r-0.955$ for this work). As pure TFE and $97 \mathrm{~T}$ are relatively acidic, weakly nucleophilic solvents, steric effects $(0.62<\delta)$ are of greater importance in determining the rates and more negative $\rho^{*}$ values $(-2.08)$ were obtained.

Considering only polar $\left(\sigma^{*}\right)$ parameter and of replacing $k_{i}$ for $\mathrm{Me}$-(1) group by $k_{80 \mathrm{~L}}$ for R-groups in $80 \mathrm{E}$ solvent system. led to the eq. (2).

$$
\log \left(k / k_{80}\right)=\rho^{*} \sigma^{*}
$$

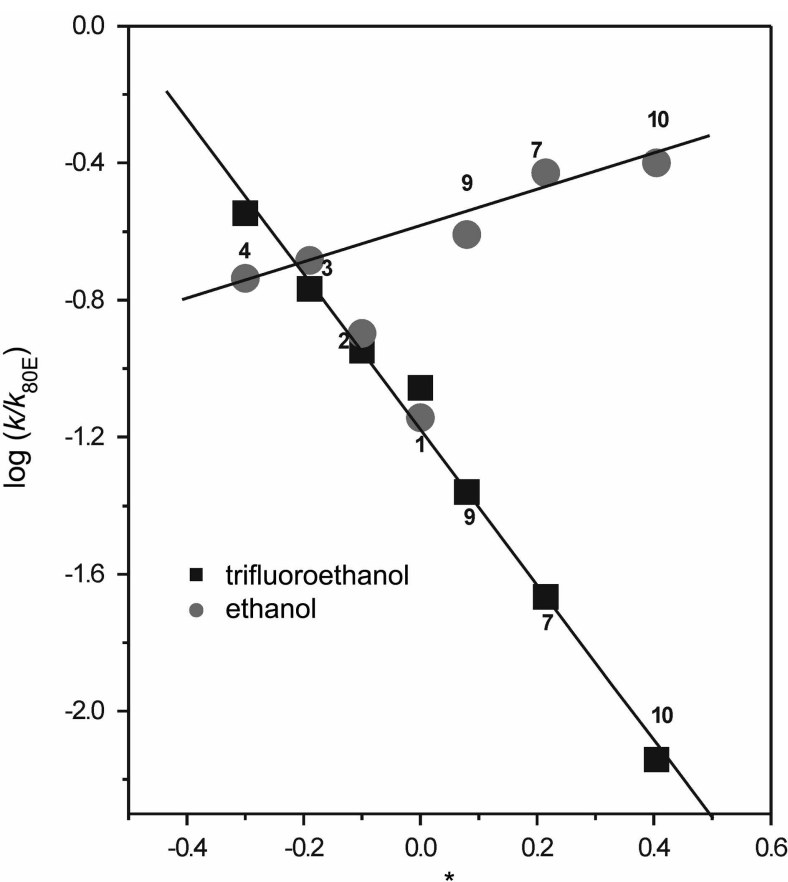

Figure I. Taft's polar relationship using the eq. (2) for solvolyses of aliphatic substituled acyl derivalives in chosen solvent systems according to structural change in the substitutents at $0^{\circ} \mathrm{C}$.

Equation (2) permits the efficient interpretation of the effect of adjacent groups (especially the downward deviation shown in Figure 1). Solvolyses in TFE give a good the $\rho \sigma^{*}$ plot (slope -2.27 . Table 3), showing reactions disfavoured by electron-withdrawing groups (EWG). For pure ethanol solvent, the points for 1,2 and 3 laid surprisingly on the same correlation line as TFE (Figure 1), indicating similar solvolysis rates in TFE and ethanol solvents. In contrast, other ethanolyses gave a correlation of small positive slope [slope $\left(\rho^{*}\right)-0.50, \mathrm{n}-5$ and $\mathrm{r}-0.964$; except for 1 and 2].

Grunwald-Winstein (GW) correlations. Correlation of solvolysis rates with changes in solvent composition has been evaluated by an one term Grunwald-Winstein (GW) eq. (3)..$^{26,31 a}$

$$
\log \left(k k_{\mathrm{SOF}}\right)=\mathrm{mY}_{\mathrm{Cl}}-\mathrm{c}
$$

In the equation (3), $k$ and $k_{80 \mathrm{E}}$ are solvolysis rates in a given solvent and $80 \mathrm{E}$ solvent system as a standard solvent, respectively and $\mathrm{Y}_{\mathrm{CI}}{ }^{2 n}$ is a solvent ionizing power parameter based on solvolysis rates of 1-adamantyl chloride as a standard substrate with $\mathrm{m}-1.00$ and the sensitivity to the change in those parameters, respectively, and $c$ is a residual (constant) term. Equation (3) has performed satisfactorily in the role as a tool of mechanistic criteria on the basis of the degree of electrophilic solvation on the ionization TS (unimolecular character) with respect to the change of solvent composition.

Introduction of $l \mathrm{~N}$ term, corresponding solvent nucleophilicity term (bimolecular character), into the eq. (3) led to the two terms (extended) GW eq. (4). ${ }^{3} 11,32$

$$
\log \left(k / k_{0}\right)=m Y_{C l}-N_{T}+c
$$


In eqn. (4), $l$ is the sensitivity to change in solvent nucleophilicity $\mathrm{N}_{\mathrm{T}}$ (based on solvolysis rates of S-methyl dibenzothiophenium ion ${ }^{2+}$ ). ${ }^{0.25}$ Multiple correlation using eq. (4) have been highly successful for solvolyses of acid

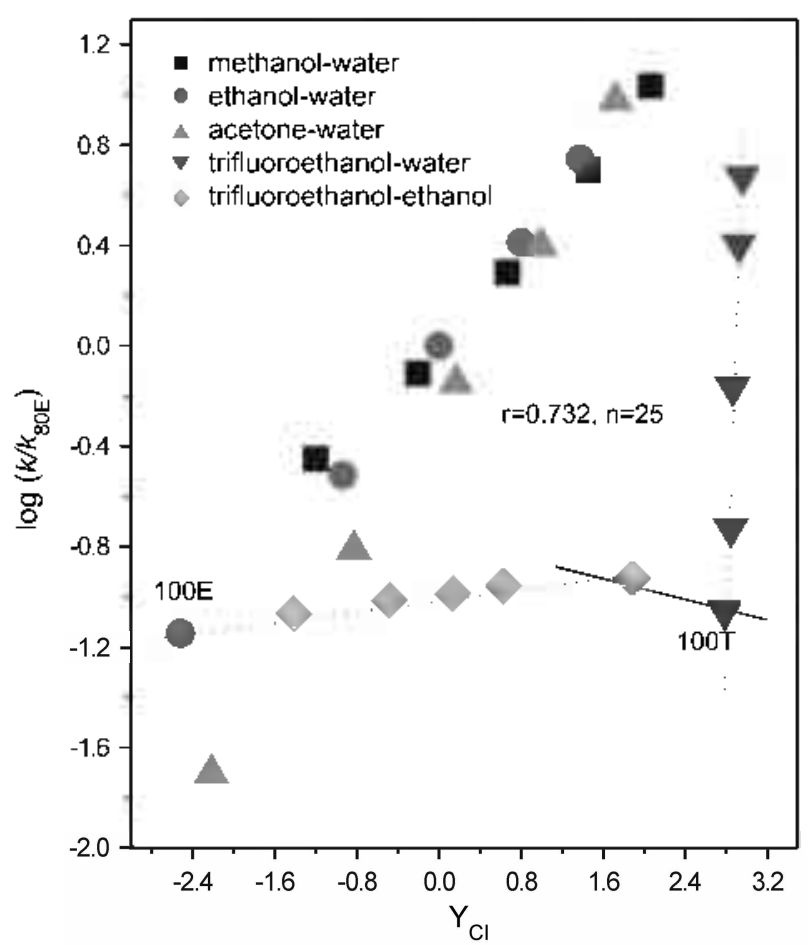

Figure 2. (irunwald-Winstcin plot for solvolyses of Acetyl chloride (1) at 0 "C. (kinetic data were guoted from rel. 14 and Table 2 in (his work).

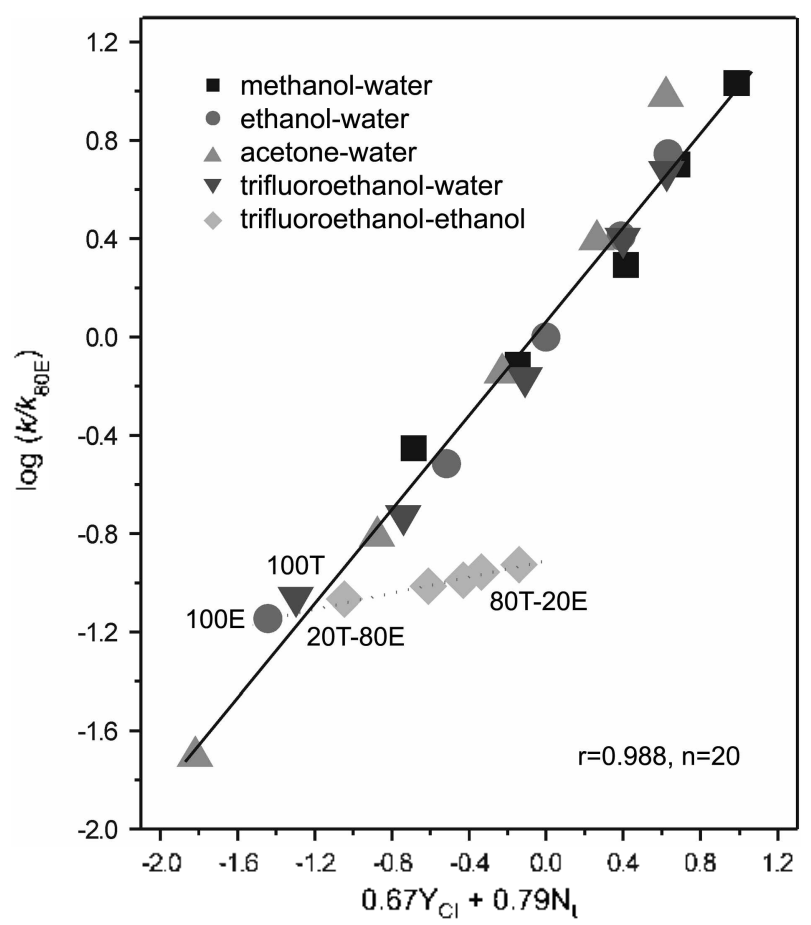

Figure 3. Extended Grunwald-Winstein plot for solvolyses of Acetyl chloride at $0^{\circ} \mathrm{C}$. (condition analyzed were shown in $g$ and $h$ footnote of Table 4 ). chlorides $^{37.39}$ reacting via a single mechanism over the range of organic solvents, and nucleophilic solvation is one cause of dispersed Grunwald-Winstein correlation (eq. 3). Further investigation of the differential reactivity in ethanolysis separated according to whether substituent is alkyl or arylaliphatic group was attempted using an one-term (eq. 3) and the two-terms (extended) Grunwald-Winstein equation (eq. 4).

Solvolyses of aliphatic substituted acyl derivatives were studied over a wide the range of aqueous organic solvents including TFE-ethanol to inquire further into the reactivity in terms of the solvent effect. These results of correlation analyses involving multiple regression on $\mathrm{Y}_{\mathrm{Cl}}$ and $\mathrm{N}_{\mathrm{T}}$ (equs. 3 and 4) are described in Table 4 and the previous results reported so far for acid chlorides are also included in Table 4 (and /or in footnotes). Typical correlations for one-term and two-terms $\mathrm{GW}$ parameter correlation in solvolyses of acetyl chloride (1) at $0^{\circ} \mathrm{C}$ are plotted in Figure 2 and 3 respectively.

Comparison between Figure 2 and 3 exhibited that the separate linear correlation in TFE-water solvent system (Figure 2) became a single linear correlation with $\log \left(k / k_{80 \mathrm{~L}}\right)$ $-(0.67+0.03) \mathrm{Y}_{\mathrm{Cl}}+(0.79+0.04) \mathrm{N}_{\mathrm{r}}+0.09+0.04(\mathrm{r}-$ 0.988 and $n-20$ ) see Figure 3 . When solvolyses rates in all solvent systems including TFE-ethanol solvent system are analyzed by eq. (4), an unacceptable correlation coefficient $\left(r^{-}-0.934\right.$ and $\left.n-25\right)$ was obtained, so that separate discussion is needed for these solvolyses. Anyway, from a single correlation in aqueous organic solvent systems

Table 4. Correlalion analyses of $\log (k i k$ son: for solvolyses of various acetyl ehlorides with the multiple parameter Grunwald Winstein cquation [(3)and (4) $]^{\text {ts }}$

\begin{tabular}{|c|c|c|c|c|c|c|c|}
\hline $\mathrm{R}$ in $\mathrm{RCOC}$ & parameter & olvent & $\mathrm{n}^{\prime \prime}$ & $\mathrm{r}^{*}$ & $m 7^{\prime f}$ & $f^{t}$ & $c^{x}$ \\
\hline $\mathrm{p}^{\prime \prime \prime}\left(0^{\circ} \mathrm{C}\right)$ & $Y_{C l} . V_{T}$ & all & 20 & 0.988 & 0.67 & 0.79 & 0.09 \\
\hline $3^{\prime \prime}\left(10^{\circ} \mathrm{C}\right)$ & $Y_{C l} . V_{T}$ & $\mathrm{f}^{\prime}$ & 6 & 0.982 & 0.81 & 0.72 & \\
\hline $4^{5}\left(0^{\circ}(\mathrm{C})\right.$ & $Y_{C l} . V_{T}$ & all & 18 & 0.994 & 0.90 & 0.75 & -0.258 \\
\hline $4\left(0^{\circ} \mathrm{C}\right)$ & $Y_{C l} . V_{T}$ & $f^{\prime}$ & 9 & 0.981 & 0.92 & 0.74 & -0.331 \\
\hline $4^{\prime \prime}\left(10^{\circ} \mathrm{C}\right)$ & $Y_{C l} . V_{T}$ & $\mathrm{P}$ & 7 & 0.987 & 0.97 & 0.74 & \\
\hline $7\left(0^{\circ} \mathrm{C}\right)$ & $Y_{\mathrm{Cl} .} . V_{T}$ & $\mathrm{e}$ & 9 & 0.989 & 0.79 & 0.95 & -0.950 \\
\hline $8^{h}\left(10^{\circ} \mathrm{C}\right)$ & $Y_{C l} . V_{T}$ & all & 33 & 0.959 & 0.42 & 1.03 & 0.031 \\
\hline $11^{k}\left(10^{\circ} \mathrm{C}\right)$ & $Y_{C I .} V_{T}$ & all & 35 & 0.963 & 0.39 & 1.02 & 0.002 \\
\hline $12^{k}\left(10^{\circ} \mathrm{C}\right)$ & $Y_{C I .} V_{T}$ & all & 33 & 0.964 & 0.46 & 1.02 & -0.016 \\
\hline $\begin{array}{l}\rho-\mathrm{NO}_{2} \mathrm{Pl}^{\prime}- \\
\left(25^{\circ} \mathrm{C}\right)\end{array}$ & $Y_{C I .} V_{T}$ & all & 34 & 0.969 & 0.54 & 1.78 & 0.110 \\
\hline
\end{tabular}

"The mulliple regression imalysis was perlonned using Origin 6.0 program using the values of solvent parameter for $\mathrm{Y}_{\mathrm{Cl}}$ and $\mathrm{N}_{\mathrm{c}}$ quoted trom ret. 26 and ref. 6. 25. "Number of solvents. "Correlation coefficient. "Susceptibility to cach solvent parameter chosen. "Value of constant obtained from the correlation. "Result analyzed using data from ref.' I4 and Tible 2 . And the result in agreement with those reported Bentley (the m 0.86 and the $/ 0.68$ ) in aqueous solvent ststem including acetic acid solvent. "Ixeept for trifluorothanol-cthanol solvent systems in cortclation. "Lor acueous fluorinated alcohol and data quoted from ref. 35. 'Result anjalyzed using data from rel.' 15 and libble 2. Solvent systems chosen lor correlation is only ligher aqueous binary mixtures known as the range of $S_{x} I$ mechanism (the dual reaction channel) (ref. 15 and ref. 16). "Result analysed using data from ref. I6 "Ouoted from ref. $37 \mathrm{~b}$ and the $\mathrm{m}$ - and the $/$ - values for solvolyses of acid chloride $S_{A} \mathrm{~N}$ pathway: 0.57 .1 .68 for PhOCOCl (rel. 37b). 0.58. 1.59 for MeOCOCl (tel. 40) and $0.46 .1 .6 \mathrm{I}$ for $\rho-\mathrm{NO}_{2} \mathrm{PhCH} \mathrm{OCOCl}_{2} \mathrm{Oref} .37 \mathrm{cl}$. respectively. 


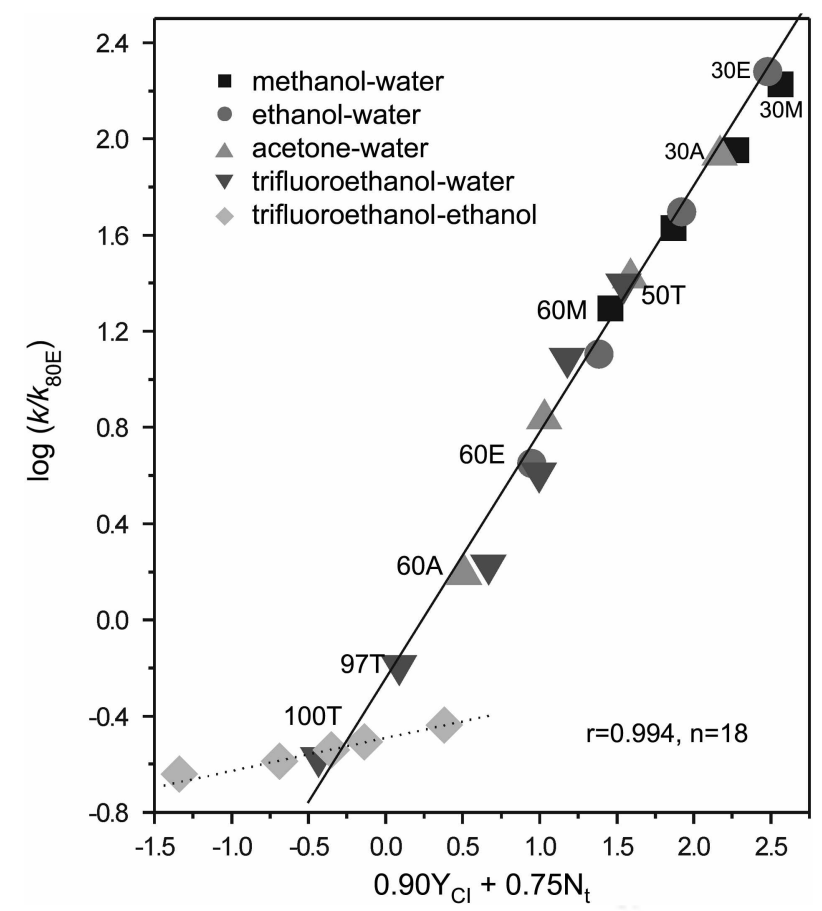

Figure 4. Extcnded Grumwald-Winstcin plot for solvolyses of trimethylacetyl chloride (4) at 0 " $\mathrm{C}$. [in case of including TFF.ethanol system. $r=0.975(\mathrm{n}=23)$ was oblained and condition analyzed are shown in g. $\mathrm{i}$ and $\mathrm{j}$ footnote of 'lable 41.

meaning a single reaction channel, the solvent effects for this reaction with a loose type $S_{x 2}$ mechanism (reported by Bentley ${ }^{14}$ ) quantitatively dissected into the contribution from solvent ionizing power $(\mathrm{m}-0.67)$ consistent with $\mathrm{C}-\mathrm{Cl}$ cleavage and solvent nucleophilicity $(l-0.79)$. But. for TFE-ethanol solvent systems, not containing water, no major change of correlation patterns were observed in Figure 2 and Figure 3.

A similar pattern to those discussed above for $\mathbf{1}$ is also seen in solvolyses of $\mathbf{4}$ (dual reaction channel) within a range of $S_{3} 1$ solvent systems at $0{ }^{\prime \prime} \mathrm{C}$. The plot for this result from multiple regression analysis with $\log \left(k / k_{810}\right)-$ $(0.90+0.03) \mathrm{Y}_{\mathrm{Cl}}-(0.75+0.03) \mathrm{N}_{\mathrm{T}}-(0.2+0.095)(\mathrm{r}-0.994$ and $n-18$ ) is shown in Figure 4.

Considering on the basis of the multiple correlation of $\mathrm{BuCl}\left(\mathrm{m}-0.86 \text { and } l-0.38 \text { for } \mathrm{S}_{\mathrm{W}} 1 \text { standard compound }\right)^{6}$ with nucleophilically-solvated cation intermediate, those of trimethylacetyl chloride $(t-\mathrm{BuCOCl}, 4)$, led by the introduction of $\mathrm{C}^{-} \mathrm{O}$ group into $t-\mathrm{BuCl}$, in rich aqueous media was considered as being a consequence of the ionization mechanism with considerably nucleophilic solvent participation (about relatively two fold the $l$ value) on developing carbocation. A greater $m$ value for $\mathbf{4}$ relative to those for $\mathbf{1}$ would be consistent with the dominant electronic effect to be expected in the presence of three methyl groups. As shown in Figure 3, the deviation (like 1) from the TFE-ethanol correlation also was displayed for solvolysis rates of 4 .

In turn, an acceptable linear correlation in aqueous organic solvents including TFE-ethanol solvent systems have been reported previously for solvolyses of substituted acyl derivatives ${ }^{16}$ containing S-atom, para-substituted benzoyl derivatives $\left(p-\mathrm{XC}_{6} \mathrm{H}_{5} \mathrm{COCl}\right)^{37 \mathrm{~d}}$ and chloroformate systems $(\mathrm{ROCOCl})^{377, c, t 0}$ and these results are described in Table 4 (and/or footnotes). Such phenomena can be explained by the similarity of mechanism caused by the similarity of the role of solvent molecules (as a nucleophile) in aqueous organic and THE-ethanol solvent systems to stabilize TS structure.

Although solvolyses of cyclopropylcarbinyl and cyclobutyl bromides were reported by Kevill ${ }^{5}$ as the reaction proceeding via the ionization mechanism with an appreciate nucleophilic solvation of carbocation (like $t$-BuCOCl), the correlation lines including the points of TFE-ethanol solvent systems (slightly below one) were shown in these solvolyses.

Consequently, solvolyses of $\mathbf{1}$ and $\mathbf{4}$ having two separate correlation lines using eqn. (4), for aqueous media or non aqueous media (TFE-ethanol solvents), can be rationalized in terms of two different modes of nucleophilic attack on the $\mathrm{C}^{-} \mathrm{O}$ group (see below).

Two third order reaction models. Nucleophilic attack by the molecule of solvent has been quantitatively evaluated by a third order reaction model, ${ }^{35.41}$ based on a general base catalyzed (GBC) reaction involving another molecule of solvent. For solvolyses in TFE-ethanol solvents. ${ }^{35+41 \mathrm{~b}}$ we could establish eq. (5) having four possible third order reactions:

$$
k_{\text {obs }}=k_{\mathrm{FF} .}[\text { ethanol }]^{2}+k_{\mathrm{TT}}\left[\mathrm{TF}[]^{2}+\left(k_{\mathrm{FT}}+k_{\mathrm{TF}}\right)[\text { ethanol][TFГ: }]\right.
$$

the letter described in the subscript of third order rate constants (k) in eq. (5) represents the role of solvents as a nucleophile (first letter) and/or as a general base (second one) (E: a molecule of ethanol and T: a molecule of TFE. e.g. $k_{\mathrm{LI}}$ term; $\mathrm{E}$ as a nucleophile and $\mathrm{T}$ as a general base). In cases where it is established that yields of trifluoroethylated products are low, equation (5) has been simplified by assuming that the main factor determining the rate constants is nucleophilic attack by ethanol, assisted by another molecule of ethanol. ${ }^{41:}$ More generally, we have shown that the rates of solvolyses of acyl chlorides, containing aromatic rings or other EWG, can be explained using eqn. (6) (in which only the $k_{\text {TT }}$ term is ignored), ${ }^{35}$ in these cases, $k_{\text {ollos }} /$ [ethanol] $]^{2}$ is linearly related to the solvent ratio [TFE] [ethanol] (Table 5), and solvolysis rates in ethanol are significantly faster than in TFE (see $k_{\mathrm{L}} / \mathrm{k}_{\mathrm{r}}$ ratios for substrates 7-12 and others in Table 5).

$$
k_{\text {ols }}\left[{ }_{\text {ethanol }}{ }^{2}=k_{\text {F.F. }}+\left(k_{\text {F.T }}+k_{\text {TFF }}\right)[\text { TFE: }] /[\text { ethanol }]\right.
$$

The slightly negative slope of the correlation using eq. (6) (Table 5) observed for solvolyses of $p$-nitrobenzoyl chloride at $10^{\circ} \mathrm{C}$ could be an expression of dominant dependence on two ethanol molecules ( $k_{L E}$ term) compared with other solvent molecules. ${ }^{+1 c}$ Benzoyl chloride showed an excellent correlation $(r-0.998$ and $n-4)$ with a slightly positive slope.

However, solvolyses of substrates 1-4 in TFE/ethanol mixtures give low $k_{\mathrm{F}} \mathrm{k}_{\mathrm{T}}$ ratios (Table 5), and are not well correlated using eq. (4) (see Figures 3 and 4). In contrast, 
Table 5. Results analysed using third order model equations $[(6)$ and $(7)]$ and selectivity $\left(k_{1} / k_{\mathrm{T}}\right)$ walues for solvolysis rates of aliphatic substiluted acelyl chloride in trifluoroethanol-ethanol solvent mixtures

\begin{tabular}{|c|c|c|c|c|c|}
\hline \multirow{2}{*}{$\mathrm{R}$ in $\mathrm{RCOCl}$} & \multicolumn{2}{|c|}{$\mathrm{A} 10^{-1} \mathrm{~s}^{-1} \mathrm{~L} \cdot \mathrm{mol} \mathrm{l}^{-2}$} & \multirow{2}{*}{$r^{k}$} & \multirow{2}{*}{ slops: Intercept } & \multirow{2}{*}{$k r / k_{\top}^{d}$} \\
\hline & slope" & intercepl ${ }^{\prime}$ & & & \\
\hline $1^{\prime}\left(0^{\circ} \mathrm{C}\right)$ & $4.33+0.14(4.37)^{t}$ & $1.41-0.15(1.39)^{\circ}$ & 0.998 & 3.07 & 0.817 \\
\hline $2^{h}\left(0^{\circ} \mathrm{C}\right)$ & & & & & 1.12 \\
\hline $3^{h}\left(0^{\circ} \mathrm{C}\right)$ & & & & & 1.21 \\
\hline $3^{\prime}\left(10^{\circ} \mathrm{C}\right)$ & $5.84+0.29(5.14)^{\prime}$ & $1.75-0.31(1.70)^{2}$ & 0.996 & 3.34 & 1.04 \\
\hline $4^{\prime}\left(0^{\circ} \mathrm{C}\right)$ & $0.488+0.017(1.06)^{f}$ & $0.213+0.017(0.197)^{2}$ & 0.998 & 2.29 & 0.647 \\
\hline $4^{\prime}\left(10^{\circ} \mathrm{C}\right)$ & $1.64+0.08$ & $0.500+0.08(0.514)^{\prime}$ & 0.997 & 3.29 & 0.710 \\
\hline $7^{\prime}\left(0^{\circ} \mathrm{C}\right)$ & $1.08+0.06$ & $0.548+0.094(0.703)^{\gamma}$ & 0.993 & 1.98 & 17.3 \\
\hline $8^{k}\left(10^{\circ} \mathrm{C}\right)$ & $0.665+0.081$ & $2.22+0.10(1.89 y$ & 0.972 & 0.30 & 129 \\
\hline $10^{\prime}\left(10^{\circ} \mathrm{C}\right)$ & 0.803 & $0.557(0.541)^{\prime}$ & 0.996 & 1.44 & 42.4 \\
\hline $11^{k, j}\left(10^{\circ} \mathrm{C}\right)$ & $0.480+0.10$ & $0.960+0.160(1.78)^{\prime}$ & 0.942 & 0.16 & 157 \\
\hline $12^{k}\left(10^{\circ} \mathrm{C}\right)$ & $1.16+0.06$ & $1.93+0.09(1.82 y$ & 0.994 & 0.6 & 77.9 \\
\hline $\mathrm{McOPhCH}_{2}-\left(10^{\circ} \mathrm{C}\right)$ & 3.44 & 1.49 & 0.99 & 2.31 & 7.42 \\
\hline $\operatorname{PhCOC}]^{m}-\left(10^{\circ} \mathrm{C}\right)$ & $(1.31+0.06) \times 10^{-2}$ & $\begin{array}{c}(6.72+0.21) \times 10^{-2} \\
\left(6.54 \times 10^{-2} y\right.\end{array}$ & 0.998 & 1.94 & $2^{\prime \prime}$ \\
\hline $\mathrm{P}-\mathrm{NO}_{2} \mathrm{PhCOC} \mathrm{I}^{m+}-\left(10^{\circ} \mathrm{C}\right)$ & $-(4.32+0.76) \times 10^{-2}$ & $0.128+0.003(0.126)^{r}$ & 0.970 & & $120^{\prime \prime}$ \\
\hline
\end{tabular}

"In case of 1,3 and 4 groups, the slope and the intercept obtained from the plot using eq. 7 (including pure TrF., but exepted 40T-F. solvent swstem) correspond to ( $k_{\mathrm{ET}}+k_{\mathrm{TE}}$ ) tem and $k_{\mathrm{T}}$ tenn. respectively. but except for these compounds. the intercept is required to be chinged as $k_{\mathrm{EE}}$ term obtained

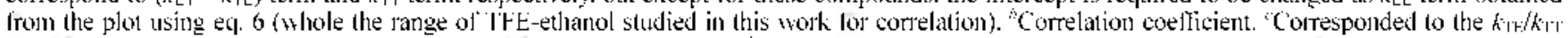
ratio. for 1.3 and 4 groups and to the $k \mathrm{~T} / k_{\mathrm{TT}}$ ratio for other compounds. "Ratio of solvolysis rates between those corresponding for pure ethatiol ( $k \mathrm{r}$ ) and

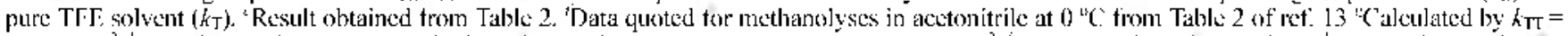

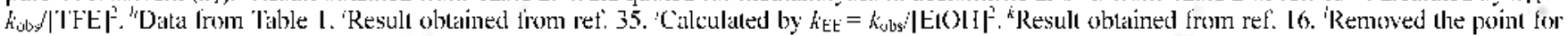
80 I-E solvent system. "Result obtained from rej. 9 (using Kinelic data in 40 I-E. 301-E. 20 I-E and 100E). "Data from rej. 9.

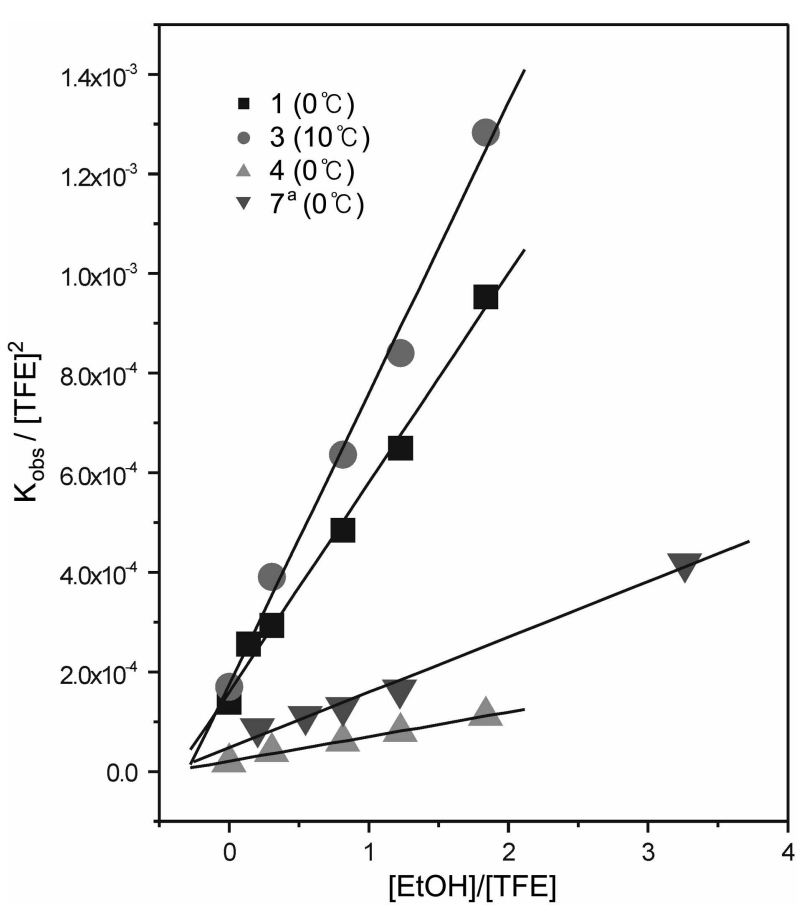

Figure 5. Plots of hiss $/[T F F]^{2} w$. molar ratio of ethanol and TFF. for solvolysis of aliphatic substituted acelyl chloride chosen in TF'L-ethanol system. "Plotted using cy. (6).

solvolyses of 12 are well correlated using eq. (4). ${ }^{16}$ To explain the results for $\mathbf{1 - 4}$, we now propose an alternative third order mechanism in which the solvent molecule assisting nucleophilic attack acts as an electrophile (not as general base). In support of this proposal, electrophilic assistance by phenol accelerates solvolyses of acetyl chloride, but retards solvolyses of chloroacetyl chloride. ${ }^{13}$ As TFE is a better electrophile than ethanol, if the $k_{\mathrm{L}: \mathrm{L}}$ term in eq. (5) is ignored, we then obtain eq. (7). Consequently, $k_{i l} /$ $|\mathrm{TFE}|^{2}$ should be linearly related to the solvent ratio [ethanol] [TFE], as found (Figure 5, Table 5).

$$
k_{\mathrm{cbs}}\left[{ }_{\mathrm{TF}}\right]^{2}=k_{\mathrm{TT}}+\left(k_{\mathrm{FT}}+k_{\mathrm{TF}}\right) \text { [ethanol]][TFГ:] }
$$

The different values of the $k_{\mathrm{L}} / \mathrm{k}_{\mathrm{c}}$ ratio for $\mathbf{4}$ from those values for other acyl chloride with alkyl groups is responsible for dual reaction channel depending on the characteristic of solvents. Relatively large $l$-values in solvolysis of aliphatic substituted acyl derivative do not seem to be a conclusive clue to the type of assistance to nucleophilic solvation (third order reactions with $\mathrm{GBC}$ or electrophilic assistance).

Kinetic solvent isotope effects (KSIEs). In the studies on acid chloride solvolyses proceeding via $\mathrm{S}_{\mathrm{f}} \mathrm{N}$ mechanisms, the determination of the values for KSIE (KSIE in methanol $\geq 2.0)^{+1 \mathrm{a}-\mathrm{c} .42}$ presented as $k_{\mathrm{ROH}} / k_{\mathrm{ROO}}$ rate ratios, provided convincing evidence for third order reactions, based on powerful $\mathrm{GBC}$ by one molecule of solvent. High values $(>1.6)^{+3 .}$ as (possible) third order ${ }^{(6) . c}$ reactions and low values $(\leq 1.2)^{44.45}$ as $\mathrm{S}_{\mathrm{N}} \mathrm{l}$ or $\mathrm{S}_{\mathrm{S}} 2$ reactions have been proposed, respectively.

KSIE values determined for this work are given in Table 6 (along with selected literatures values). New results for $\mathrm{CF}_{3} \mathrm{CH}_{2} \mathrm{OD}$ are included, and values corresponding to the range of $\mathrm{S}_{32} / \mathrm{S}_{* 1} 1$ reaction mechanisms were observed. These results support the exclusion of the $k_{T T}$ term (proposed in eq. 
Table 6, liiss order constants $\left(h / \mathrm{s}^{-1}\right)$ in methanol and trilluoroelhanol for kinetic solvent isolope elfect (KSIIss)

\begin{tabular}{|c|c|c|c|}
\hline $\mathrm{R}$ in $\mathrm{RCOCl}$ & methanol & methanol- $L^{f^{t}}$ & $\begin{array}{l}\text { Airorl" } \\
\text { imot" }\end{array}$ \\
\hline $2\left(0^{\circ} \mathrm{C}\right)$ & $(4.06+0.03) \times 10^{-2}$ & $(2.85 \perp 0.07) \times 10^{-2}$ & 1.42 \\
\hline $5\left(0^{\circ} \mathrm{C}\right)$ & $(4.33+0.09) \times 10^{-2}$ & $(3.12 \perp 0.07) \times 10^{-2}$ & 138 \\
\hline $8\left(10^{\circ} \mathrm{C}\right)$ & & & $1.80^{d t}$ \\
\hline$\left(0^{\circ} \mathrm{C}\right)$ & $(7.99+0.04) \times 10^{-2}$ & $(5.41+0.20) \times 10^{-2}$ & 1.48 \\
\hline $10\left(10^{\circ} \mathrm{C}\right)$ & & & $1.6 \mathrm{l}^{d}$ \\
\hline \multicolumn{3}{|c|}{$\rho-\wedge O_{2} I^{\prime} h-\left(25^{\circ} \mathrm{C}\right)$} & $2.27^{\circ}$ \\
\hline \multicolumn{3}{|l|}{$11\left(10^{\circ} \mathrm{C}\right)$} & $1.68^{t}$ \\
\hline \multicolumn{3}{|l|}{$12\left(10^{\circ} \mathrm{C}\right)$} & $1.48^{\prime}$ \\
\hline & trifluoros & tritluor: & \\
\hline $1\left(0^{\circ} \mathrm{C}\right)$ & $(2.67 \pm 0.01) \times 10^{2}$ & $(2.64 \pm 0.02) \times 10^{2}$ & $1.01^{\circ}$ \\
\hline $3\left(0^{\circ} \mathrm{C}\right)$ & $(1.40 \pm 0.07) \times 10^{2}$ & $(1.34 \pm 0.03) \times 10^{2}$ & $1.04^{h}$ \\
\hline $4\left(0^{\circ} \mathrm{C}\right)$ & $(3.60 \pm 0.01) \times 10^{3}$ & $(3.53 \pm 0.01) \times 10^{i}$ & $1.02^{\prime}$ \\
\hline $7\left(0^{\circ} \mathrm{C}\right)$ & $(1.23 \pm 0.01) \times 10^{3}$ & $(1.23 \pm 0.01) \times 10^{i}$ & $1.00^{k}$ \\
\hline $\mathrm{C}: \mathrm{DI}^{\prime} \mathrm{M}^{\prime}\left(0^{\circ} \mathrm{C}\right)$ & $(1.16 \pm 0.02) \times 10^{1}$ & $(1.04 \pm 0.02) \times 10^{1}$ & $1.12^{\prime \prime \prime}$ \\
\hline
\end{tabular}

"Determined under the same conditions as shown in footnote a in Table 5 . Methanol- $L$ ) was Aldrieh $(99.5 \%$ D). ' Kinctic solvent isotope eftect. "Data from ref I6. 'Data Iron ref." 4 lb. 'Trilluoroethenol- $I$ ) was Aldrich (290\% D). "1.32 of KSIE in methanol from rel. $16 . " 1.37$ ol KSIE in methanol from tef. 16 . '1.46 of $\mathrm{KSIV}$. in methatol from tef. 16 and 1.55 for $\mathrm{PhCOCl}$ from ref. 14, 'Rate constant measured for $\mathrm{K}$ SIF: was within the range of standard deviation. when compared previous the result of rate constant $\left|k=(1.18 \perp 0.06) \times 10^{-3}\right|$ obtiined als shown in Table 1 . "1.40 of $\mathrm{KSIF}$ in methanol trom ref., 16. "Chlorodiphenyl methanc. "1.06 of KSIT: it methanol at $35^{\circ} \mathrm{C}$ trom ref, 46.

6), and show the absence of GBC by a TFE molecule. The slightly higher value of 1.12 for chlorodiphenylmethane $(\mathrm{CDPM})^{\text {to }}$ can be rationalized as the result of a degree of electrophilic assistance.

Leffler's isokinetic relationship ${ }^{3:}$ (eq. 8), a linear relationship showing the compensation effect between activation enthalpies and entropies of a series of reactions related by structural change, was applied to solvolyses of acetyl chloride over a wide range of substituents.

$$
\delta \Delta \mathrm{H}^{*}=\beta \delta \Delta \mathrm{S}^{*}
$$

For the plot for pure ethanol and TFE solvents, a linear plot with the isokinetic temperature $(\beta-268.2 \mathrm{~K} ; \mathrm{r}-0.996$ and $n-12$ in Figure 6) separates these relationship into two parts, one having a good linear correlation and another showing deviations above the line. Most points form a straight line consisting of activation parameters for all ethanolyses of all substrates (except for 4). This result means that these ethanolyses are within the same series of reactions controlled by structural changes in a bimolecular TS. The points for solvolyses of $\mathbf{1 , 2}$ and 3 in pure TFE lie on this same line (like Figure I) with similar slope $(\beta-254.5 \mathrm{~K})$. but a different intercept was observed for $\mathbf{4}$ possibly due to steric hindrance. ${ }^{47}$

For all solvolyses of arylaliphatic substrates (7-11) in TFE, the scattered points again show positive deviations from the linear correlation and the degree of the deviation appears to be related to the $k_{\mathrm{L}} / k_{\mathrm{J}}(>1)$ terms and/or the $\left(k_{\mathrm{LI}}+k_{\mathrm{VE}}\right) / k_{\mathrm{LL}}$ term. Such phenomena are attributed to the lesser role of TFE as nucleophile at the formation of TS structure.

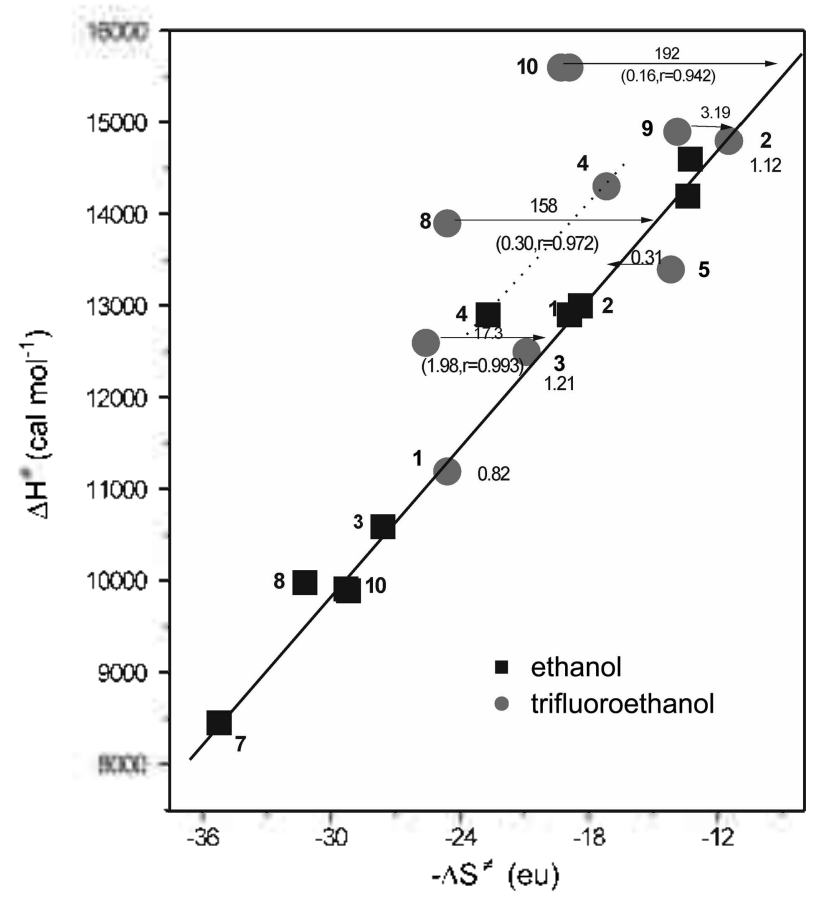

Figure 6. Isokinetic relationship: plots of $\Delta \mathrm{I}^{+}$ws. $\Delta S^{+}$for solvolyses of aliphatic substituted acy 1 derivatives in $100 \%$ wthanol and $100 \%$ itilluoroethanol solvent systems according to structural change in substituents [numerals: $\left(k_{1} / k_{\mathrm{j}}\right.$. parenthesis; $\left(k_{\mathrm{l}} \mathrm{T}+k_{\mathrm{r}}\right)$ ) k:.r.l.

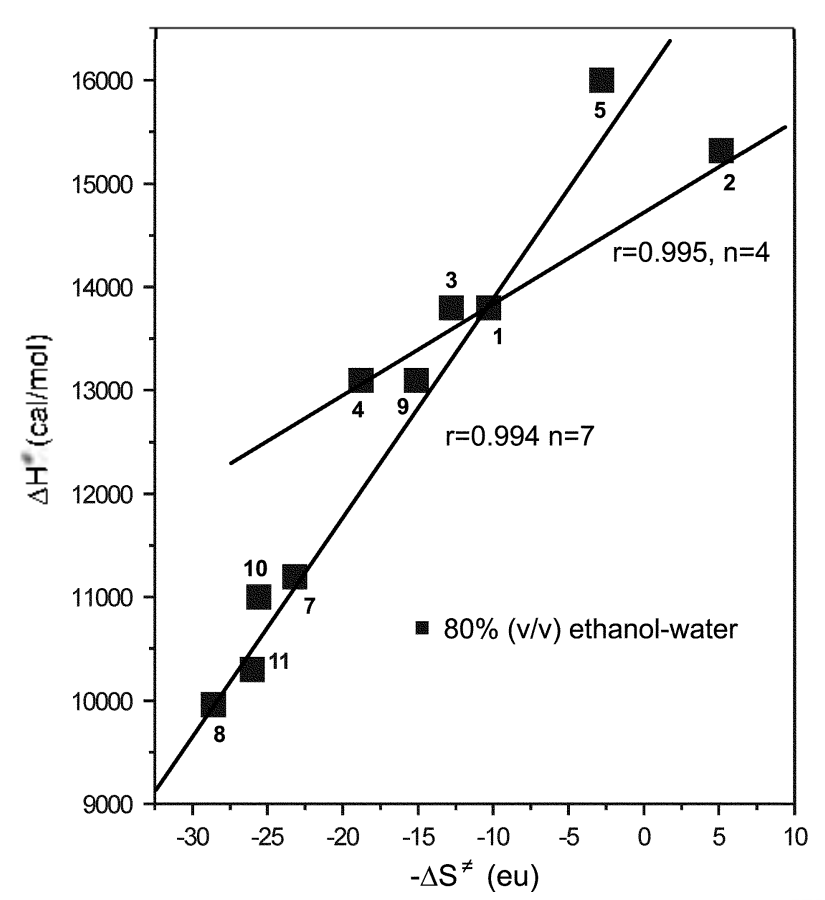

Figure 7. Isokinetic relationship: plots of $\Delta H^{ \pm}$vs. $\Delta S^{ \pm}$for solvolyses of aliphatic substituted acyl derivalives in $80 \%(\mathrm{v} / \mathrm{v})$ ethanol-water solvent systems according to structural change in substituents. Isokinetic temperature. $\beta=226.7^{\circ}(r=0.994 . n=7)$ and $\beta=91.38^{\circ} \mathrm{C}(\mathrm{r}=0.995 \mathrm{n}=4)$.

For $80 \%(\mathrm{v} / \mathrm{v})$ ethanol-water, two separate linear correlations with $\beta-226.7 \mathrm{~K}(\mathrm{r}-0.994$ and $n-7)$ for arylaliphatic substrates (as well as for $\mathbf{1}$ and $\mathbf{5}$ ) and with $\beta-91.4 \mathrm{~K}$ 
$(r=0.995$ and $n=4)$ for 1.2.3 and 4 were observed (Figure 7). Isokinetic relationships for substituted acyl derivatives in our work show a high sensitivity to polar aqueous media (particularly alkỵl groups). Consequenty. in this solvent system. these reaction depended on the solvent effect (rather than electronic effect) were controlled by entropy $\left(\Delta \mathrm{S}^{+}\right)$ value because the $\beta$ values are less than the experimental temperature $\left(\beta<\mathrm{T}_{\text {exp }}\right)$.

\section{Conclusion}

Successful applications of third order models using the eqns. (6) and (7) for solvolỵses of aliphatic substituted acỵl derivatives ( $\mathrm{S}_{*} 2 / \mathrm{S}_{*} 1$ process) in TFE-ethanol solvent systems depend on whether arylaliphatic or alkyl groups are present. The different contributions of third order rate constants obtained from linear correlation with positive slopes were shown to be the $k_{\mathrm{EE}}$ and the $k_{\mathrm{TE}}$ terms for ary laliphatic and the $k_{\mathrm{TT}}$ and $k_{\mathrm{ET}}$ (TFE molecule in a specific role as an electrophile) terms for alkyl groups. respectively. The contributions from the $\left(k_{\mathrm{ET}}+k_{\mathrm{TE}}\right) / k_{\mathrm{EE}}$ terms analyzed for ary laliphatic substituted acyl derivatives increase in the order $\mathbf{9}<\mathbf{7}<\mathbf{1 0}<\mathbf{8}<\mathbf{1 1}$ group. providing strong support for the fact that the ratio of those third rate constants are not dependent on the degree of the solvent micleophilic participation (the / values) in the rate determining step (rds) but TS stnicture favoring electrophilic solvation. Solvolytic reactions of those derivatives with alkyl groups undergoing the positive charge developing on the $\mathrm{C}=\mathrm{O}$ group in the rds fit eq. (7) and could be mainly controlled a molecule of TFE solvent acting as a electrophile.

Taft's polar correlation (Figure 1) and isokinetic relationship (Figure 6) with the phenomena of collinearity. the results analyzed by Grunwald-Winstein parameter and KSIE effects have confirmed as the nucleophilic solvent participation (reflected alkyl groups favoring carbocation TS) in solvoly ses of those derivatives with alkyl group. but for arylaliphatic substituted acyll derivatives. solvolyses which proceed through the nucleophilic solvation of TS with no the adjacent effect were observed.

\section{Experimental Section}

Materials. Solvents used for kinetics were dried and distilled by standard methods except for 1,1,1.3.3.3-hexafluoro-2-propanol (HFIP. 99\%), methanol-D (>99.5\% D) and trifluoroethanol- $D(>99 \% \mathrm{D})$ which used Aldrich reagents without distillation. Aqueous fluorinated solvent mixtures were prepared by mixing appropriate weights at ambient temperatures. Accurate water contents of $97 \%$ (w/w) TFEwater and $97 \%(w / w)$ HFIP-water mixture were determined by a Karl Fisher titration (Model: ORION AF instrument) using (Hydranal composite $5 \mathrm{~K}$ reagent (precision: $0.3 \%$ at $\operatorname{lmg~} \mathrm{H}_{3} \mathrm{O}$ ). TFE-ethanol and other solvent mixtures were prepared by volume percentage $(\% \mathrm{v} / \mathrm{v})$.

Solvolyses of aliphatic substitutes acetyl chlorides ( $\mathrm{RCOCl}$ ) used Aldrich reagents for: $\mathrm{R}=\mathrm{Me}(1$. purity $98 \%$ ):
$\mathrm{R}=\mathrm{Et}(\mathbf{2}, 98 \%): \mathrm{R}=i-\operatorname{Pr}(3.98 \%): \mathrm{R}=t-\mathrm{Bu}(\mathbf{4} .99 .6 \%): \mathrm{R}=$ clloromethyl $(6.98 \%): \mathrm{R}=$ benzyl $(7.98 \%): \mathrm{R}=$ thiophenỵlmethỵl $(8,98 \%) \mathrm{R}=$ : 2-phenethỵl $(9.98 \%): \mathrm{R}=$ diphenỵlmethỵl (10. 97\%): and $\mathrm{R}=$ phenylthiomethyl $(\mathbf{1 1}$. 97\%). and used Lancaster reagents for $\mathrm{R}=$ cyclophenylmethyl $(5,98 \%)$ : without distillation and/or recrystallization.

Kinetic methods. The rate constants were determined using a general conductimetric method ${ }^{35}$ which were performed by the Origin 6.0 program using the Guggenheim equation ${ }^{49}$ from data monitor automatically.

Acknowledgement. We are grateful to Choi. S. H., Park. B. N. Lee, C .S and Ban, J. Y.. for helpful experimental assistance.

\section{References}

1. (a) Bentley: T. W: Carter, G. E. J. Am. Chem. Soc. 1982, 104 . 5741. (b) Bentley. T. W. Carter. G. E.; Roberts. K. J. Org. Chem. 1984. 49.5183.

2. (a) Liu. K.-T.: Sheu. H. I.: Chiu. P. F.: Hu. C. R. Tetrahedron Lett. 1990. 31. 3611. (b) Kevill. D. N.: Ismail. H. J.: D'Souza. M. T. J. Org. Chem. 1994, 59.6303. (c) Fujio, M; Saeki. Y; Nakamoto. K. Yatsugi, K.; Goto. M.: Kim, S. H.: Tsuji. Y.: Rappoport, Z: Tsuno. Y. Bull. Chem So. Jpn. 1995, 68. 2603. (d) Fujio. M: Susuki. I: Yatsugi. K.: Saeki. Y:: Goto. N.: Kim. S. H.: Isuji. Y.: Rappoport. Z: Tsun1o. Y. Bull. Chem. Soc. Jpm. 1995. 68. 2619.

3. Takeuchi. K.: Ohga. Y.: Ushino. T: Takasuka. M. J. Org. Chent. $1997.62,4904$.

4. (a) Takeuchi, K.: Okazaki, T:; Ushino. T:: Ueda, K.: Endo, T: Notario. R. J. Org. Chem. 2001. 25. 2034.

5. Kevill. D. N.: Abduljaber. M. A. J. Ong. Chem 2000. 65. 2548.

6. Kevill. D. N.: D'Souza. M. T. J. Chent. Res. (S) 1993. 174.

7. Bentley. T. W.: Llewellyt1. G.: Ryu. Z. H. J. Org. Chent 1998. 63. 4654.

8. Ja Roza. D. A.: Andrews, L. J:- Keefer. R. M J. Ant Chem. Soc 1973. 17,7003

9. Lee. I.: Koo. I. S.: Sohn1. S. C.: Lee. H. W. Bull. Korean Chem. Soc. 1982.3.92

10. Bentley. T. W.: Harris. H. C. J. Chem. Perkin Trans. 2 1986. 619.

11. Patai, S. The Chentistry of Acy Halides (especially Chapter 6); Interscience (John Wiley \& Sons), Stonebridge Press: 1976.

12. Kevill. D. N.: Daum. P. H.: Sapre, R. J. Chem. Soc. Perhin Trans. 2 1975.963

13. Kevill. D. N.: Kim. C. B. J. Chem Soc. Perkin. Trans. 21988. 1353.

14. Bentley. T. W.: Llewellyn. G.: McAlister. J. A. J. Org Chent 1996. 61,7927.

15. Bentley. T. W: Shim, C. S. J. Chem. Soc. Porhin Trans. 21993. 1659.

16. Ryu. Z. H.: Shin. S. H.: Lee. T. P.: Lim. G. T.: Bentley. T. W. d. Chent. Soc. Perkin Trans. 22002.1283.

17. Kwonl. D. S.: Park. H. S.: Um. I. H. Bull. Korem Chem. Soc. 1991. 12,93.

18. Hogan. J. C.: Gandour. R. D. J. Org. Chem. 1991. 56. 2821

19. (a) Koh. H. J: Han, K. L.: Lee, H. W.: Lee, I. Bull Koman Chem. Soc. 2002. 23. 715. (b) Koh. H. T.: Lee. I. J. Org. Chem 1999. 64. 4783. (c) Koh. H. T.: Shin. C. H.: Lee. H. W.: Lee. I. J. Chem. Soc. Perkin Trans. 21998.1329

20. Lee. H. W.: Yun, Y. S.; Lee, B. S.: Koh, H. J.: Lee. I. J. Chent Soc Parkin Trans. 22000.2302.

21. (a) Castro. E. A.: Santander, C. L. J. Org. Chem. 1985. 50,3595 (b) Castro. E. A.: Freudenberg. M. J. Org. Chem 1980. 45.906.

22. Kaspi. T.: Rappoport. Z. Tetrahedron Lent. 1977. 2035.

23. Raber. D. T.: Neal. W. C.. Ir.: Dukes. M. D.: Harris. J. M.: Mount. 
D. L. J. Am. Chem. Soc, $1978,100,8187$.

24. Kevill. D. N.: Anderson. S. W. J. Ong. Them. 1991. 56. 1845.

25. Kevill. D. N. In Atrances in Ouantative Siructure Propert Retationship. Charton. M.. Ed.: JAI Press: Greenwich. CT. 1996: Vol. $1, p 181$.

26. Bentley T. W. Llewellyn. G. Prog. Phws. Org Chem 1990. I7. 121

27. Mukherjee. L. M.: Grunwald. E. J. Phys. Chem. Soc. 1951. 62. 1311.

28. Bentley. T. W.: Schadt. F. L.: Schleyer. P. v. R. J. Am. Chem. Soc. 1972, 91, 992 .

29. Raber D. J.; Dukes. M. D.: Gregory. J. Tetrahedron Lett. 1974, 8. 667.

30. Taft T. W. In Steric Effects in Organic Chemishy (chapter 13); Newman. M. S. Ed.: Wiley: New York. 1956.

31. (a) Grumwald. E.: Winstein. S. J. Ant. Chem. Soc. 1948, 70. 846. (b) Kevill. D. N.: D'Souza. M. J. Phws. Org Chem. 1992. 5. 287.

32. (a) Schadt. F. L.: Bentler: T. W.: Schleyer. P. \&. R. J. Am. Chem. Soc. 1976. 98. 7667. (b) Bentlev. T. W.: Schlever, P. v. R. Ad: Plys. Org. Chem. 1977. 14. I. (c) Liu. K.-T. J. Chimese Chem. Soc. 1995. t2. 607 .

33. Kevill. D. N.: D'Souza. M. J. J. Chent. Res. (S) 1996. 1649.

34. Leffler. I. E.: Grunwald. E. Rates and Equilibria of Organic Reactions: Wiley: New York. 1963.

35. Oh, O. H.: Jang. G. G.: Lim. G. T.: Ryu. Z. H. Bull Konam Chem. Soc. 2002, 23, 1089

36. Shoter. J. Corretation Anallsis of Organic Reactivity: With Particular Reference to Multiple Regression (especially Chapter 4): John Wiley \& Sons Ltd.. Research Studies Press: 1982.
37. (a) Kevill. D. N.: Oldfield, A. J.; D'Souza. M. J. $J$. Chem. Res. (S) 1996. 122. (b) Kevill. D. N.: D'Souza. M. J. J. Chem. Soc. Perhin Trans. 2 1997. 1721. (c) Kyong. T. B.: Park. B.-C.: Kim. C.-B.: Kevill. D. N. J. Org. Chem. 2000. 65. 8051. (d) Kevill. D. N.: DSouza. M. J. J. Phus. Org. Chem. 2002. 15.881.

38. Liu. K.-T.: Chen, H.-I. J. Chent. Soc. Perkin Trans. 22000.893.

39. Ryu. Z. H. Ju. C.-K : Sung. D. D; Sung. N. C. Bentlev. T. W. Bull. Korean Chem. Soc. 2002. 23. 123.

40. Kevill. D. N.: Kim. T. C.: Kyong. T. B. J. Chem. Res. (S) 1999. 150 .

41. (a) Bentley, T. W. Jones. R. O. J. Chem. Perkin Trans. 21993. 2351. (b) Bentley. T. W. Jones. R. O.: Koo. I. S. J. Chem. Soc. Porkin Trans. 2 1994. 753. (c) Bentlev. T. W: Ebdon. D: Llewellyn, G.: Abduljabor. M. H: Miller. B.: Kevill. D. N. $d$. Chem. Soc. Dalton Trans. 1997. 3819. (d) Bentley. T. W.: Eldon. D. N. J. Phus. Org Chent 2001. 1f. 759.

42. Koo. I. S.: Yang. K.: Kang. K.: Lee. I.: Bentley. T. W. J. Chent Soc. Perkin Trans. $21998,1179$.

43. Koo, I. S.; Lee. I; Oh, J.: Yang. Y.: Bentley. T. W. J. Phys. Org. Chem $1993,6,223$

44. Bentley. T. W.: Koo. I. S.: Normant. S. T. .J. Org. Chem 1991. 56. 16014.

45. Laughton. P. M.: Robertson. R. E. Solute-Sohent Interaction: Coetzee. J. F; Ritchie, C. D., Eds; Marcel Dekker: New York, 1969: $\mathrm{p} 319$

46. Chang. S.; Koh. H. J.; Lee. B; Lee. I. d. Ong Chom 1995. 60. 7760 .

47. Ingold. C. K. Ouart. Ren: (London) 1957. H. 1.

48. Cason1. T.: Kraus. K. W. J. Org. Chem. 1961. 26. 2624.

49. Guggenheim. E. A. Phil. Mag. 1926, 2.538. 